\title{
O exame Celpe-Bras como instrumento direcionador de tarefas para o ensino de Português para Falantes de Espanhol
}

\author{
Ana Lígia Barbosa de Carvalho e Silva \\ Maria Gabriela Silva Pileggi \\ Universidade Estadual de Campinas - Unicamp
}

\begin{abstract}
Resumo
Este artigo tem por objetivo descrever e analisar duas tarefas que compõem um curso de português para falantes de espanhol, nível inicial, para estudantes universitários que participam de intercâmbios acadêmicos no Brasil. As tarefas foram elaboradas à luz do construto do exame Celpe-Bras, que avalia as quatro habilidades (compreensão oral e escrita, produção oral e escrita) de forma integrada e que tem como foco o uso da língua em situações realistas de comunicação. Com a criação do exame, seus idealizadores já pensavam em um possível efeito retroativo (washback effect) benéfico no ensino de línguas. Os resultados deste estudo indicam que o exame exerceu efeito retroativo positivo na elaboração de material didático, pois verificou-se a integração de habilidades nas tarefas apresentadas, potencializando o aprendizado da língua em situação próxima à realidade dos participantes, no mundo real. As limitações para este estudo foram explicadas e sugestões para novas investigações foram feitas.
\end{abstract}

Palavras-chave: Celpe-Bras. Efeito retroativo. Elaboração de material didático. Habilidades integradas.

\begin{abstract}
This article aims to describe and analyze two tasks that were used in a basic Portuguese course for Spanish speakers, who were exchange graduate students in Brazil. The tasks were designed in the light of the construct of Celpe-Bras exam, which assesses the four skills (oral and written comprehension, oral and written production) in integrated tasks, which focus on the usage of language in realistic communication settings. With the development of the exam, its designers already thought of a possible beneficial washback effect to the teaching of languages. The results of this study show that the exam had a positive washback effect on the design of material, as an integration of abilities could be noticed in the tasks presented, enhancing the learning of language in a situation that is close to the reality encountered by the participants in the real world. Limitations to this study were explained and suggestions for further investigations were made.
\end{abstract}

Keywords: Celpe-Bras. Washback effect. Material design. Integrated skills.

\section{INTRODUÇÃO}

O ensino de Português como Língua Estrangeira (PLE), para que seja eficaz e atenda os propósitos de uso da língua pelos aprendizes, não deve pautar-se unicamente no ensino isolado de conteúdos léxico-gramaticais. Em razão disso, o construto do exame Celpe-Bras, 
desde seus primórdios, propõe uma concepção diferenciada de língua/linguagem, e consequentemente de proficiência, voltada para o uso, e não o conhecimento da língua. Esta é a abordagem que fundamenta este artigo, cujo objetivo é descrever e analisar duas tarefas (Anexo A) utilizadas em um curso básico de português para falantes de espanhol, ministrado em um centro de estudos de línguas de uma universidade pública paulista.

A questão problematizadora deste artigo diz respeito à possibilidade de o construto do exame Celpe-Bras ser tomado como ponto de partida para a elaboração de tarefas para o ensino de português para falantes de espanhol. Dessa forma, o exame funcionaria como um instrumento redirecionador, com um potencial efeito retroativo positivo da avaliação no processo de ensino/aprendizagem. Conforme afirma Scaramucci (2005, p. 37), exames como o Celpe-Bras "[...] podem ser vistos como instrumentos direcionadores potenciais desse ensino, definindo conteúdos, competências e habilidades desejáveis".

Este artigo está organizado da seguinte forma: além desta introdução e das considerações finais, descrevemos brevemente o exame Celpe-Bras e seus fundamentos teóricos, com destaque para o construto, a noção de proficiência, a definição do conceito de tarefas integradas e o possível efeito retroativo benéfico desse exame. Em seguida, prosseguimos com descrição das duas tarefas, que são, por fim, analisadas.

\section{O EXAME CELPE-BRAS}

O Celpe-Bras (Certificado de Proficiência em Língua Portuguesa para Estrangeiros), desenvolvido pelo ministério da Educação (MEC), aplicado no Brasil e no exterior com o apoio do Ministério das Relações exteriores (MRE), é o único certificado de proficiência em português como língua estrangeira reconhecido oficialmente pelo governo brasileiro. No exterior, é aceito por diversas empresas e instituições. É exigido pelas universidades brasileiras "para ingresso em cursos de graduação e em programas de pós-graduação, bem como para validação de diplomas de profissionais estrangeiros que pretendem trabalhar no país" (BRASIL, 2015, p. 8).

O exame é dividido em duas partes: Parte Escrita e Parte Oral. A Parte Escrita é subdividida em quatro tarefas que buscam avaliar a compreensão oral e escrita e a produção escrita de forma integrada. Na Tarefa 1, o examinando assiste a um vídeo, a partir do qual é convidado a produzir um texto escrito. Na Tarefa 2, o examinando ouve um áudio e é convidado a produzir um texto escrito. Já nas Tarefas 3 e 4, o ponto de partida para a produção escrita é a leitura, ou seja, o examinando lê um texto fonte e é convidado a produzir 
seu próprio texto. Assim, em todas as quatro tarefas da Parte Escrita do exame os examinandos produzem um texto dentro de uma situação de comunicação, integrando diferentes habilidades. Na Parte Oral, com duração aproximada de 20 minutos, o examinando conversa com um examinador (interlocutor) e é avaliado por ele e também por outro examinador (observador) sobre assuntos variados, que são apresentados por meio de elementos provocadores, que são pequenos textos e imagens de temas variados. Na Parte Oral, a integração de habilidades também ocorre, uma vez que são avaliadas a compreensão oral e a produção oral. A integração de habilidades é assim vista por seus elaboradores:

[...] diferentemente dos exames de proficiência que testam em separado as quatro habilidades (compreensão oral, compreensão escrita, produção oral e produção escrita), o Celpe-Bras avalia esses elementos de forma integrada, ou seja, como ocorrem em situações reais de comunicação. (BRASIL, 2013, p. 5)

Por meio de um único exame, são certificados quatro níveis de proficiência: Intermediário, Intermediário Superior, Avançado e Avançado Superior.

\section{FUNDAMENTOS TEÓRICOS PARA A ELABORAÇÃO DAS TAREFAS}

A concepção teórica que permeia o exame está materializada no Manual de Orientações para os Coordenadores de Postos Aplicadores do Exame Celpe-Bras, BRASIL $(2015)^{1}$, que, em suas diretrizes, explicita as "denominações construídas que visam referenciar o teste teoricamente, fundamentando o que chamamos de construto do exame" (PILEGGI, 2015, p.13).

O termo construto refere-se a um construto psicológico, uma conceitualização teórica sobre um aspecto do comportamento humano que não pode ser medida ou observada diretamente. Exemplos de construtos são inteligência, motivação para o rendimento, ansiedade, rendimento, atitude, dominância e compreensão em leitura (EBEL; FRISBIE, 1991 apud SCARAMUCCI, 2009, p.32).

O exame busca avaliar a proficiência no uso da língua em situações realistas de comunicação, através de tarefas que são um convite para o examinando interagir no mundo integrando, nas tarefas da Parte Escrita do exame, as habilidades de compreensão (oral e escrita) e produção escrita, e na Interação face a face, compreensão (oral) e produção oral (BRASIL, 2015).

Em cada tarefa, o examinando deve demonstrar sua capacidade de mobilizar tanto recursos linguísticos como interacionais para fazer uso da língua com um propósito social. $\mathrm{O}$

\footnotetext{
${ }^{1}$ O Manual de 2015 foi a versão mais recente encontrada no acervo do Celpe-Bras. Disponível em: < http://www.ufrgs.br/acervocelpebras/arquivos/manuais/manual-do-aplicador-2015>. Acesso em: 09 fev. 2018.
} 
Celpe-Bras apresenta-se, então, como um exame de desempenho, ou "teste de performance", pois avalia as capacidades linguísticas por meio de atividades de comunicação cujas evidências são coletadas por meio de simulação de tarefas, em um contexto do mundo real (MCNAMARA, 2000).

O referido Manual, BRASIL (2015, p. 9), traz em seu bojo o conceito de proficiência que norteia o exame, baseado no "[...] uso adequado da língua para desempenhar ações no mundo", considerando-se sempre a situação de comunicação, o propósito, e o(s) interlocutor(es) envolvidos na interação com o texto. Cada tarefa, portanto, é pautada pelos seguintes aspectos discursivos: propósito, interlocução (enunciador e interlocutor) e gênero.

Há que se ressaltar, ainda, que o exame traz uma integração entre língua e cultura, não bastando apenas o domínio estruturalista de itens léxicos e/ou gramaticais, de forma isolada. Nesse sentido, é possível afirmar que o conceito de proficiência que fundamenta o exame não é visto de forma absoluta, mas sim relativa, pois procura levar em conta a especificidade da situação de uso futuro da língua (SCARAMUCCI, 2000).

\section{Tarefas integradas}

Com o advento dos testes de desempenho - que se propõem a avaliar o uso da língua, e não apenas estruturas -, torna-se cada vez mais frequente o uso de tarefas que integram mais de uma habilidade (compreensão oral e escrita, produção oral e escrita). Tanto é assim que vários estudos na área de avaliação, segundo Gebril (2018), têm se ocupado de tópicos como o construto de avaliações integradas, a confiabilidade e a validade de tarefas integradas, o impacto da proficiência no desempenho, bem como o modo como os alunos usam "fontes externas" (textos escritos, ou não) em sua produção escrita.

Essas tarefas, também chamadas de reading-to-write tasks ou reading- listeningwrite tasks (ASENCIÓN, 2008; PLAKANS, 2008; GEBRIL; PLAKANS, 2009) surgem em exames de LE mais recentes, em oposição aos testes de itens isolados - como os testes de múltipla escolha. As tarefas integradas não podem, então, ser confundidas com testes integrativos, já que estes não são testes de desempenho. Ainda que testes como o cloze e o ditado possam ser considerados integrativos, estão longe do que se faz em situações de comunicação (SCARAMUCCI, 2016).

Dessa forma, as tarefas integradas caracterizam-se por solicitar que o examinando demonstre seu desempenho em uma situação de comunicação de uso da língua, que se aproxime ao máximo de uma situação do "mundo real", através da mobilização de duas ou 
mais habilidades integradas (PILEGGI, 2015; 2017). A sua utilização nos testes de desempenho se justifica, uma vez que esses testes apresentam a língua de forma contextualizada, criando condições para que o examinando possa demonstrar sua proficiência de forma direta em situação semelhante à realidade (MCNAMARA, 1996; SCARAMUCCI, 2005).

Podem-se destacar, ainda, algumas vantagens das tarefas integradas:

\begin{abstract}
Em primeiro lugar, fornecem aos examinandos múltiplos meios de demonstrar sua proficiência em diferentes habilidades, uma vez que, sendo as habilidades requeridas de forma integrada, o examinando tem a oportunidade de mobilizar mais que uma habilidade para realizar a tarefa. Em segundo lugar, melhorar o efeito retroativo do teste nas práticas de ensino e aprendizagem, visto que as tarefas integradas replicam o uso da língua em situações realistas de comunicação essa prática pode servir para que o ensino deixe de ser estruturalista. Em terceiro lugar, aumentam a autenticidade dos testes promovendo situações de comunicação com as quais os examinandos podem se deparar no uso da língua fora do teste. (PILEGGI, 2015, p. 129)
\end{abstract}

Diante disso, o presente trabalho, baseando-se no construto do exame Celpe-Bras, descreve tarefas, para uso em sala de aula, que buscam motivar os alunos a produzirem textos que os aproximem de suas atividades cotidianas na sociedade, integrando habilidades.

\title{
Efeito retroativo
}

Exames de alta relevância - testes em que decisões importantes são tomadas com base em seus resultados - geram impacto ou influência "nos processos educacionais, seus participantes e produtos do ensino e aprendizagem" (SCARAMUCCI, 2004, p 203). Tal fenômeno é conhecido na literatura da área de avaliação como efeito retroativo, (washback effec, washback, backwash). Scaramucci (2004) levanta cinco possíveis dimensões dentro das quais o efeito retroativo pode variar: especificidade (geral e específico), intensidade (forte ou fraco), extensão (longo ou curto), intencionalidade (intencional e não intencional) e valor (positivo e negativo).

Alderson e Wall (1993, p.117) afirmam que "[...] a hipótese do efeito retroativo parece assumir que professores e alunos fazem coisas que de outra forma não necessariamente o fariam" (tradução nossa, grifo dos autores) ${ }^{2}$. Por conseguinte, como ressalta Scaramucci $(2005$, p. 213), “[...] quanto maior o status e prestígio da língua e do exame, maior o efeito retroativo por ele exercido". A mesma autora alerta, entretanto, que os efeitos de um exame poderão ser tanto positivos como negativos, já que seria uma visão

\footnotetext{
2 "The washback Hypothesis seems to assume that teachers and learners do things they would not necessarily otherwise do because of the test".
} 
ingênua e determinista imaginarmos que um bom exame produza sempre efeitos positivos (SCARAMUCCI, 2004).

De acordo com Rodrigues e Scaramucci (2008), um exame como o Celpe-Bras pretende maximizar ou potencializar as possibilidades de um efeito retroativo benéfico e minimizar as chances de efeito maléfico, uma vez que os alunos " [...] ao se prepararem para o exame estariam ao mesmo tempo preparando-se para compreender e produzir textos orais e escritos na vida real” (RODRIGUES; SCARAMUCCI, 2008, p. 128).

Vale lembrar que exames de proficiência de alta relevância podem potencialmente produzir efeitos não somente em examinandos, ou em agentes do processo de ensino/aprendizagem (professores, alunos, diretores, entre outros), como também nos processos educacionais (materiais, currículo, metodologia, estratégias de aprendizagem) e nos produtos do ensino (aquilo que de fato é aprendido), como ensina Bailey (1996; 1999). Nesse sentido, Hughes (1983) e Scaramucci (1995) asseveram que é muito mais provável ocorrer um ensino de línguas comunicativo quando a avaliação também é comunicativa, fazendo com que o efeito retroativo do exame seja benéfico ao ensino de línguas. Em um estudo recente, McKinley e Thompson (2018) asseguram que trinta anos de pesquisas têm demonstrado a influência significativa que a avaliação exerce no ensino de línguas.

\section{Material didático}

Não obstante as vantagens do uso de um livro didático como material de apoio às aulas no curso em foco, optou-se pela utilização de material próprio, de modo que o conteúdo das tarefas, além de ser autêntico - criado e veiculado socialmente e não voltado exclusivamente para o uso em sala de aula - mais se aproxima à realidade e ao uso da língua pelos alunos, que estão imersos em um ambiente de aprendizagem de português como segunda língua (L2). Sobre a autenticidade e a adaptação de material autêntico, Long (2015), seguindo uma abordagem de ensino de línguas por tarefas (Task-Based Language Teaching TBLT), sustenta que o material autêntico deve ser modificado, especialmente em estágios iniciais, a depender do propósito e dos objetivos do curso, de modo que o insumo modificado se adeque melhor à capacidade de processamento do aluno. Textos simplificados distinguemse de textos autênticos, já que os primeiros utilizam linguagem mais acessível - lexicalmente menos sofisticada e sintaticamente menos complexa - tornando-os mais fácil de serem compreendidos (CROSSLEY, 2018).

Huback (2012) salienta que, em geral, os livros didáticos de português para estrangeiros apresentam um enfoque fundado principalmente em exercícios gramaticais. 
Soma-se a isso o fato de haver no mercado poucas opções de livros didáticos voltados, especificamente, para o ensino da língua portuguesa para falantes de espanhol, e que tenha foco em aspectos funcionais, pragmáticos discursivos e culturais para o ensino da língua.

Nesse sentido,

[...] a lacuna de LDs de português específicos para hispano-falantes deveria incluir, também, materiais baseados não apenas numa análise contrastiva entre os sistemas do português e do espanhol, mas também em comparações de ordem funcional, pragmática, discursiva e cultural (DINIZ; STRADIOTTI; SCARAMUCCI, 2009, p. 276)

Com isso, decidiu-se que o material didático para o curso Português para falantes de espanhol I, aqui abordado, seria produzido pela equipe de professores do curso, com a finalidade de fornecer subsídios para que os alunos pudessem desenvolver compreensão e produção oral e escrita em língua portuguesa. As aulas tinham por objetivo apresentar e discutir questões linguísticas e sócio-histórico-culturais de maneira que os alunos se tornassem potencialmente capazes de participar de atividades acadêmicas e sociais na universidade e em outros espaços de convívio. Assim, na direção de uma abordagem crítica para o ensino e a aprendizagem de línguas, concordamos com Silva e Quitzau (2016, p. 11), ao afirmarem que "[...] durante o processo de ensino-aprendizagem de uma língua adicional, seja ela qual for, em contexto escolar, os alunos devem posicionar-se como sujeitos sociais críticos, conscientes, engajados, participantes do universo dialógico da linguagem".

$\mathrm{Na}$ esteira do que asseveram Diniz, Stradiotti e Scaramucci (2009), também as "visões, crenças e valores" das professoras foram fatores que contribuíram para a escolha do conteúdo das tarefas propostas para o grupo. A ideia, durante o curso apresentado, era sempre propor atividades que provocassem reflexões sobre temas diversos, sem perder de vista a situação específica de ensino/aprendizagem, ou seja: i) um grupo de universitários falantes de espanhol; ii) nível básico; iii) aprendizes de português como L2, isto é, em situação de imersão na língua. Assim como Diniz, Stradiotti e Scaramucci (2009, p. 277), entendemos que em tal situação cabe ao professor “[...] indicar ao aprendiz diferentes maneiras de atentar para essa linguagem, trabalhando estratégias que permitam sua observação e sistematização", tendo como foco o aspecto funcional, pragmático, discursivo e cultural da língua, e não apenas de estrutura, léxico, ou ainda questões de nível fonético-fonológico.

A fim de possibilitar a mobilização de diversas competências no uso da língua respaldamo-nos, para a elaboração das tarefas, nos ensinamentos de teóricos da área de Aquisição de Segunda Língua (Second Language Acquisition - SLA), como Ellis (1999) e 
Skehan e Foster (2001), para quem diferentes áreas do desempenho do aprendiz de L2 competem entre si pela utilização dos recursos disponíveis, devido a limitações da capacidade de atenção. Assim, como uma maneira de se buscar um equilíbrio no processamento de forma e conteúdo, esses autores sugerem a utilização de tarefas que direcionem a atenção do aprendiz para níveis mais altos de precisão e/ou complexidade no uso da língua.

\section{DESCRIÇÃO E ANÁLISE DAS TAREFAS}

\section{Os cursos de português para estrangeiros em questão}

Os cursos Português para falantes de espanhol I e II, Português para falantes de outras línguas I e II, Português para estrangeiros III e produção de texto para alunos avançados, oferecidos no centro de ensino de línguas onde as tarefas foram elaboradas, têm como proposta fazer com que os alunos construam competência de uso da língua na interação com textos, com os participantes da sala de aula e com o meio social no entorno, por meio da realização de tarefas e projetos. Os programas enfatizam o uso da língua em situações de interação e a participação ativa dos alunos, permitindo que se posicionem de forma autoral na construção dos discursos.

A turma do curso Português para falantes de espanhol I, no segundo semestre de 2017, era composta por dez estudantes intercambistas de graduação e pós-graduação em diversas áreas do conhecimento, originários de países como Chile, Colômbia, Espanha, México, Paraguai, Peru e Venezuela. Uma professora responsável e outras duas doutorandas em Linguística Aplicada, estas participantes do Programa de Estágio Docente (PED), ministraram, durante um semestre, duas aulas semanais de duas horas de duração cada e, conjuntamente, elaboraram o material didático necessário. Os alunos, a todo tempo, mostraram-se bastante motivados para o aprendizado de português como L2, já que por ela estavam amplamente envolvidos, tanto no ambiente acadêmico como social.

\section{Tarefa 1}

Após discussão, em aulas anteriores, sobre os temas "Consumismo" e "O uso de celulares", foi proposta ao grupo uma tarefa de compreensão escrita, integrada com compreensão e produção oral, cujo tema problematizava os direitos do consumidor no Brasil e nos diversos países de origem dos alunos. 


\section{Compreensão escrita, produção e compreensão oral}

Inicialmente, foram apresentados, em aula, o Código de Defesa do Consumidor brasileiro e o site do Procon (Órgão de defesa dos direitos do consumidor). Esta primeira etapa, ou Pré-tarefa, teve por finalidade oferecer informações autênticas, atuais e relevantes sobre o tema. Em um segundo momento, os alunos efetuaram a leitura de um texto fonte ${ }^{3}$, encontrado na internet, porém adaptado ao nível dos alunos (Anexo A), cujo tema era "Direitos do consumidor". Por fim, os alunos foram divididos em pequenos grupos para discutir questões sobre o texto, que exigiam capacidade de compreensão escrita, não somente sob o enfoque da decodificação de informação, mas também, e principalmente, quanto à capacidade de se fazer inferências e compreender implícitos. A discussão nos grupos foi norteada pela seguinte pergunta que a professora deixou exposta no quadro:

1- Que situações motivam alguém a procurar o Serviço de Atendimento ao Consumidor (SAC) de um estabelecimento comercial, ou o órgão de proteção ao consumidor (Procon)? Resposta esperada: quando o produto está estragado, o serviço é ruim e em casos de publicidade enganosa ou abusiva.

2- Como agir e o que exigir, se você não estiver satisfeito com uma compra ou um serviço? Resposta esperada: primeiramente, tentar solucionar a questão com o estabelecimento fornecedor do produto ou serviço. Em seguida, procurar o Procon.

\section{Compreensão e produção oral por meio de role-play}

Dando sequência à execução da tarefa, os grupos foram separados em duplas para um pequeno diálogo, em forma de role-play, simulando uma situação que, eventualmente, poderia ocorrer a qualquer aluno no dia a dia. O enunciado completo da tarefa está no Anexo A. Um dos alunos é o comprador de um celular e o outro o atendente do Serviço de Atendimento ao Consumidor (SAC) de uma loja de eletrônicos. A conversa gira em torno de uma reclamação do cliente ao observar que a bateria do celular adquirido não funcionava adequadamente, enquanto o outro aluno, que faz o papel de atendente, tenta solucionar o problema.

Salientamos o fato de que grande parte das capacidades linguísticas (léxicogramaticais) necessárias para o desempenho da Tarefa 1, aqui analisada, já tinham sido trabalhadas em aulas anteriores. Por exemplo, o verbo "carregar", em português, nos tempos

\footnotetext{
${ }^{3}$ Escolhemos o termo "texto fonte", também utilizado no exame de entrada da Unicamp, para nos referir ao texto escrito que serve de insumo para a realização de uma tarefa.
} 
presente e passado, que comumente é utilizado por alunos falantes de espanhol como, “cargar”, já havia sido tópico de explicação anterior. Assim, conforme os ensinamentos de Ellis (1999) e Skehan e Foster (2001), durante a realização da Tarefa 1, o foco de atenção dos alunos, desviado de aspectos eminentemente linguísticos - foco na forma -, pode voltar-se para outros aspectos da comunicação, como a fluência e a interação - foco no conteúdo/significado -, com o uso de estratégias comunicativas diversas, como a paráfrase, o pedido de repetição, de clarificação, entre outras.

Durante a realização desta etapa, a professora monitorou os diálogos das duplas, circulando pela sala e fazendo anotações para correções e comentários, que ocorreram em seguida, numa etapa Pós-tarefa, com todo o grupo.

\section{Tarefa 2}

Partindo-se da suposição de que a conversa simulada entre o cliente e o atendente do SAC da loja de eletrônicos, na Tarefa 1, não solucionou o problema suscitado com relação ao suposto celular, surgiu uma nova tarefa, a Tarefa 2, desta vez com o propósito de desenvolver a capacidade de produção escrita dos alunos.

\section{Produção escrita, a partir das discussões anteriores.}

A fim de encontrar subsídios para a tarefa de produção escrita - tendo como base os elementos que também devem nortear as tarefas da parte escrita do exame Celpe-Bras (gênero, interlocutor e propósito) -, os alunos teriam que retomar o texto fonte e recordar-se do conteúdo das discussões levantas em duplas, na Tarefa 1. Com o propósito de sustentar a argumentação, eles deveriam realizar, na Tarefa 2, uma reclamação escrita fundamentada, agora dirigida não mais à loja de eletrônicos, mas ao Procon, que, conforme eles puderam conhecer na etapa de Pré-tarefa, seria órgão máximo para solucionar o problema de modo ainda amigável, em instâncias não judiciais. O enunciado completo da Tarefa 2 encontra-se no Anexo A.

A Tarefa 2, por exigir maior tempo de execução, foi designada para ser entregue na aula posterior. Após uma primeira correção, a professora devolveu as tarefas aos alunos para reescrita. Por fim, todos foram convidados a publicar seus textos na plataforma digital Googleclass, compartilhada pela turma e pelas professoras. 


\section{CONSIDERAÇÕES FINAIS}

Procuramos demonstrar, neste artigo, como o exame Celpe-Bras pode servir como um instrumento direcionador para a elaboração de tarefas em curso de português como L2, nível básico, a partir de experiências com um grupo de alunos universitários falantes de espanhol. Foi utilizado material autêntico e adaptado pelas professoras, de acordo com as necessidades, interesses e capacidade de processamento linguístico dos alunos, tendo em vista a integração das quatro habilidades, compreensão e produção oral, compreensão e produção escrita.

O foco deste trabalho centralizou-se no impacto que o exame pode exercer na elaboração de material didático, tão somente, não fazendo parte do recorte de nossas análises as potenciais influências do exame - positivas ou negativas - em professores e alunos. Tal opção justifica-se devido a questões pertinentes à ética em pesquisas, que implicariam em autorizações específicas, tanto da parte dos alunos como da instituição onde se desenvolveram as aulas, para que a produção textual dos alunos pudesse ser apresentada e analisada. Os textos produzidos, corrigidos e revisados foram compartilhados pelos alunos na plataforma online Google Classroom, disponibilizada apenas para acesso restrito aos membros do grupo, ou seja, alunos e professoras do curso. Não obstante, o processo de ensino e aprendizagem, bem como a interação dos alunos com as tarefas e a análise da produção textual, em si, podem suscitar novos e instigantes estudos.

Os resultados deste trabalho indicam uma maximização do efeito retroativo benéfico - tanto proveniente das tarefas da Parte escrita como da Parte Oral do exame Celpe-Bras - na elaboração das tarefas utilizadas como material didático, confirmando o que vários autores têm reiterado no sentido de que um ensino de línguas voltado para o uso da língua, que de fato empodere os falantes para se tornarem verdadeiros cidadãos no mundo na língua do outro, é mais provável ocorrer como fruto de uma avaliação que seja, igualmente, voltada para propósitos comunicativos.

\section{REFERÊNCIAS}

ALDERSON, J. C. Assessing Reading. Cambridge: Cambridge University Press, 2000. (Cambridge Language Assessment). Disponível em:

$<$ http://dx.doi.org/10.1017/CBO9780511732935 >. Acesso em: 28 maio 2014.

ALDERSON, J. C.; WALL, D. Does washback exist? Applied Linguistics, Oxford, v. 14, p. 
116-129, 1993. Disponível em: < https://academic.oup.com/applij/articleabstract/14/2/115/224706 >. Acesso em: 12 fev. 2018.

ASENCIÓN, Y. D. Investigating the reading-to-write construct. Journal of English for Academic Purposes, Oxford, v. 7, n. 3, p. 140-150, 2008. Disponível em: < http://www.sciencedirect.com/science/article/pii/S1475158508000362 >. Acesso em: 14 mar. 2015.

BRASIL. Ministério da Educação. Guia do participante: tarefas comentadas que compõem a edição de abril de 2013 do exame. 2013. Disponível em: <

http://download.inep.gov.br/outras_acoes/celpe_bras/estrutura_exame/2014/guia participante celpebras_caderno_provas_comentadas.pdf $>$. Acesso em: 09 fev. 2018.

BRASIL. Ministério da Educação. Manual de orientação para os Coordenadores de Postos Aplicadores do Celpe-Bras. Brasília: MEC, INEP, 2015. Disponível em: < http://www.ufrgs.br/acervocelpebras/arquivos/manuais/manual-do-aplicador-2015 >. Acesso em: 09 fev. 2018.

CROSSLEY, S. A. Authentic and Simplified Texts. In: The TESOL Encyclopedia of English Language Teaching. P. 1-7. Disponível em: < http://onlinelibrary-

wiley.ez88.periodicos.capes.gov.br/doi/10.1002/9781118784235.eelt0465/abstract $>$. Acesso em: 02 mar. 2018.

CUMMING, A. Assessing Integrated Writing Tasks for Academic Purposes: Promises and Perils. Language Assessment Quarterly, v.10, n.1, p. 1-8, Canadá, 2013. Disponível em; < http://www.tandfonline.com/doi/pdf/10.1080/15434303.2011.622016?needAccess $=$ true $>$. Acesso em: 12 fev. 2018.

DINIZ, L. R. A.; STRADIOTTI, L. M.; SCARAMUCCI, M. V. R. Uma análise panorâmica de livros didáticos de português do Brasil para falantes de outras línguas. In: DIAS, R. \& CRISTOVÃO, V. L. L. (orgs.) O livro didático de língua estrangeira: múltiplas perspectivas. Campinas, SP: Mercado de Letras, 2009.

ELLIS, R. Options in grammar teaching. In: ELLIS, Rod. SLA Research and Language Teaching. Oxford: Oxford University Press, 1997. Cap. 3. p. 77-93.

GEBRIL, A.; PLAKANS, L. Investigating Source Use, Discourse Features, and Process in Integrated Writing Tests. Spaan Fellow Working Papers in Second/Foreign Language Assessment, Ann Arbor, v. 7, p. 47-84, 2009.

Disponível em:

$<$ http://www.researchgate.net/publication/237836160_Investigating_source_use_disc ourse_features_and_process_in_integrated_writing_tests $>$. Acesso em: 16 mar.

2015 .

GEBRIL, A. Integrated-Skills Assessment. In: The TESOL Encyclopedia of English Language Teaching. p. 1-7. Disponível em: $<\underline{\text { http://onlinelibrary- }}$ wiley.ez88.periodicos.capes.gov.br/doi/10.1002/9781118784235.eelt0544/abstract $>$. Acesso em: 02 mar. 2018. 
HUBACK, A. P. O exame do Celpe-Bras e os materiais didáticos de português como língua estrangeira. (CON)TEXTOS linguísticos. Vitória, v. 6, n. 7, p. 31-46, 2012. Disponível em: $<$ http://www.ufrgs.br/acervocelpebras/arquivos/textos-publicados/huback-ana-paula $>$. Acesso em: 09 fev. 2018.

HUGHES, A. Testing for Language Teachers. Cambridge: Cambridge University Press, UK, 1989.

LONG, M. H. Second Language Acquisition and Task-Based Language Teaching. Malden, MA: Wiley-Blackwell, 2015.

MCKINLEY, J.; Thompson, G. Washback Effect in Teaching English as an International Language. In: The TESOL Encyclopedia of English Language Teaching. p. 1-12.

Disponível em : $<$ http://onlinelibrary-

wiley.ez88.periodicos.capes.gov.br/doi/10.1002/9781118784235.eelt0656/abstract $>$. Acesso em: 02 mar. 2018.

MCNAMARA, T. F. Measuring second language performance. Londres: Longman, 1996. $323 p$.

Language Testing. Oxford: Oxford University Press, 2000.

MESSICK, S. Validity and Washback in Language Testing. Educational Testing Service, Princeton, N.J., 1996.

PILEGGI, M. G. S. Tarefas integradas nos exames de proficiência CELPE-BRAS e

TOEFL iBT. 2015. 1 (145 p.). Dissertação (mestrado) - Universidade Estadual de Campinas, Instituto de Estudos da Linguagem, Campinas, SP.

. Integração de habilidades: perspectiva histórico-teórica e operacionalização no

exame Celpe-Bras. ESTUDOS LINGUÍSTICOS, São Paulo, 46 (2): p. 577-592, 2017. DOI:

http://dx.doi.org/10.21165/el.v46i2.1677

PLAKANS, L. Comparing composing processes in writing-only and reading-to-write test tasks. Assessing Writing, Oxford, v.13, n. 2, p.111-129, 2008. Disponível em:

$<$ http://www.sciencedirect.com/science/article/pii/S107529350800041X>. Acesso em: 14 mar. 2015.

RODRIGUES, M. S. A.; SCARAMUCCI, M. V. R. Compreensão (oral e escrita) e produção escrita no exame Celpe-Bras: análise de desempenho de candidatos hispanofalantes. In: WIEDEMANN, L.; SCARAMUCCI, M. V. R. Português para falantes de espanhol: ensino e aquisição. Campinas: Pontes, 2008. 268 p.

SCARAMUCCI, M.V.R. O projeto CELPE-Bras no âmbito do Mercosul: contribuições para uma definição de proficiência comunicativa. In: ALMEIDA FILHO, J.C. (Org.), Português para Estrangeiros: Interface com o Espanhol. Campinas: Pontes, 1995. p. 77-90.

Proficiência em LE: considerações terminológicas e conceituais. Trabalhos em Linguística Aplicada, Campinas, v. 36, p. 11-22, 2000. 
Efeito Retroativo da Avaliação no ensino/Aprendizagem de Línguas: O Estado da Arte. In: Trabalhos em Linguística Aplicada. 43(2):203-226, Campinas, 2004.

SCARAMUCCI, M.V.R. Prova de redação nos vestibulares: educacionalmente benéfica para o ensino/aprendizagem da escrita? In: FLORES, V do N. et al. (org.). A redação no contexto do Vestibular 2005 - a avaliação em perspectiva. Porto Alegre: Editora UFRGS, 2005. p. 37-57.

Avaliação da Leitura em Inglês como Língua Estrangeira e Validade de Construto. Calidoscópio (UNISINOS), São Leopoldo, v. 7, p. 30-48, 2009.

A avaliação de habilidades integradas no exame Celpe- Bras. In: ALVAREZ, M. L. O.; GONÇALVES, L. (Orgs.). O mundo do português e o português no mundo afora: especificidades, implicações e ações. 2016

SILVA, A. L. B. C.; QUITZAU, L. A. A sala de aula crítica: um novo olhar para o livro didático em cursos de línguas adicionais. Pesquisas em Discurso Pedagógico, [s.1.], v. 2017, n. 1, p.1-14, 23 jun. 2017. PUC. http://dx.doi.org/10.17771/pucrio.pdpe.30319. Disponível em: $<$ https://www.maxwell.vrac.pucrio.br/rev_pdpe.php? strSecao $=$ fasciculo $\&$ fas $=30370 \& N r S e c a o=X 2>$. Acesso em: 09 fev. 2018 .

SKEHAN, P.; FOSTER, P. Cognition and Tasks. In: ROBINSON, P. Cognition and Second Language Instruction. Cambridge: Cambridge University Press, 2001. Cap. 7. p. 183-204

\section{AS AUTORAS}

Ana Lígia Barbosa de Carvalho e Silva é Doutoranda e Mestra em Linguística Aplicada pelo Departamento de Linguística Aplicada (DLA) do Instituto de Estudos da Linguagem (IEL) da Universidade Estadual de Campinas, Unicamp, com bolsa CAPES. Especialista em Recursos para o Ensino de Inglês como Língua Estrangeira pela Universidade Presbiteriana Mackenzie, SP. É examinadora e avaliadora da parte oral do Exame de Proficiência em Português para Estrangeiros (Celpe-Bras). Por mais de 20 anos, tem atuado como professora de inglês como língua estrangeira para adultos, com especial interesse em inglês no contexto da aviação militar. É membro do Grupo de Estudos em Inglês Aeronáutico, GEIA (ICEA Instituto de Controle do Espaço Aéreo). Interessa-se por estudos na área de Ensino e Avaliação de Línguas Estrangeiras, Inglês para Fins Específicos e Inglês para Aviação.

E-mail: analigiasilva7@gmail.com

Maria Gabriela Silva Pileggi é doutoranda em Linguística Aplicada pelo Departamento de Linguística Aplicada (DLA) do Instituto de Estudos da Linguagem (IEL) da Universidade Estadual de Campinas, bolsista CAPES. Mestra em Linguística Aplicada, área de concentração Linguagem e Educação, pelo DLA do IEL da Universidade Estadual de Campinas. Licenciada em Letras - Habilitação em Língua Portuguesa pela Unicamp. Professora de Português para Estrangeiros do Núcleo de Línguas (NucLi) do programa Idiomas sem Fronteiras (IsF). Atua na área de avaliação em língua estrangeira, com ênfase no Certificado de Proficiência em Língua Portuguesa para Estrangeiros (Celpe-Bras). Interessa- 
se por estudos de validade, exames de proficiência, integração de habilidades e ensino de Português Língua Estrangeira/Segunda Língua/Adicional.

E-mail: pileggimg@gmail.com 


\section{Anexo A - Texto fonte e enunciados das tarefas}

LA 167 D - Português para Falantes de Espanhol 1

Temas: Consumismo / Publicidade e Propaganda

Texto fonte: Adaptado da Cartilha do consumidor. Disponível em: < http://www.procon.al.gov.br/legislacao/cartilhadoconsumidor.pdf $>$. Acesso em: 02/09/2017

\section{1) INTRODUÇÃO}

Os direitos do consumidor são fundamentais para que a cidadania seja exercida. Antigamente não existia, no Brasil, uma lei que protegesse as pessoas que comprassem um produto ou contratassem qualquer serviço. Se você comprasse um produto estragado, ficava por isso mesmo. Se o vendedor quisesse trocar, trocava, mas se não quisesse trocar, você ficava no prejuízo e não tinha a quem recorrer. Em março de 1991 entrou em vigor a Lei no 8.078/90, que é mais conhecida como Código de Defesa do Consumidor (CDC). Esta lei veio com toda a força para proteger as pessoas que fazem compras ou contratam algum serviço.

2) DIREITOS BÁSICOS DO CONSUMIDOR (Art. 6º do Código de Defesa do Consumidor - CDC)

- Proteção da vida e da saúde;

- Educação para o consumo;

- Liberdade de escolha de produtos e serviços;

- Informação. Todo produto deve trazer informações claras sobre sua quantidade, peso, composição, preço, riscos que apresenta e sobre o modo de utilizá-lo. Antes de contratar um serviço você tem direito a todas as informações de que necessitar;

- Proteção contra publicidade enganosa e abusiva. O consumidor tem o direito de exigir que tudo o que for anunciado seja cumprido. Se o que foi prometido no anúncio não for cumprido, o consumidor tem direito de cancelar o contrato e receber a devolução da quantia que havia pago. A publicidade enganosa e a abusiva são proibidas pelo Código de Defesa do Consumidor. São consideradas crime (art. 67, CDC);

- Proteção contratual;

- Indenização;

- Acesso à Justiça;

- Facilitação da defesa dos seus direitos;

- Qualidade dos serviços públicos.

3) PUBLICIDADE (Arts. 30, 35, 36, 37, 38, CDC)

Publicidade é a propaganda de um produto ou serviço. Toda publicidade deve ser fácil de se entender. O Código proíbe publicidade enganosa ou abusiva. Publicidade enganosa é a que contém informações falsas e também a que esconde ou deixa faltar informação importante sobre um produto ou serviço. Estas informações podem ser sobre:

- características;

- quantidade;

- origem;

- preço; 
- propriedades

Uma publicidade é abusiva se:

- gerar discriminação;

- provocar violência;

- explorar medo ou superstição;

- aproveitar-se da falta de experiência da criança;

- desrespeitar valores ambientais;

- induzir a um comportamento prejudicial à saúde e à segurança.

Tudo o que for anunciado deve ser cumprido, exatamente como foi anunciado. As informações da propaganda fazem parte do contrato.

4) VOCÊ PODE EXIGIR (Art. 35, CDC):

- exigir o cumprimento do que foi anunciado;

- aceitar outro produto ou prestação de serviço de valor igual, ou;

- desfazer o contrato, com direito a receber o valor pago com correção, e ser indenizado pelas perdas e danos.

\section{5) COMO E ONDE RECLAMAR}

\section{PROCURE O FORNECEDOR}

Muitas empresas já possuem o Serviço de Atendimento ao Consumidor - SAC, que atende às reclamações e procuram resolver o problema. Você pode encontrar o telefone do $\mathrm{SAC}$ nas embalagens dos produtos. Quando for reclamar conte, em detalhe, tudo o que aconteceu, para ajudar a resolver seu problema. Leve a nota fiscal, pedidos, certificado de garantia, contrato, recibos e outros documentos que tiver. Depois de reclamar, guarde com você a prova de sua queixa: protocolo, código de reclamação, etc. Não se esqueça de anotar o nome e o cargo da pessoa que o atendeu. Guarde sempre a nota fiscal dos produtos que você comprou e os recibos dos valores que pagou em caso de prestação de serviços. Só com estes documentos você pode reclamar, por exemplo, de um produto com defeito ou de um serviço mal feito.

\section{RECORRA A UM ÓRGÃO DE PROTEÇÃO AO CONSUMIDOR}

Se você não resolver seu problema com o fornecedor de um produto ou serviço, procure o PROCON, órgão de defesa dos direitos do consumidor. Já existem Procons em todas as capitais e em diversas cidades do interior. Os Procons ajudam você a resolver seu problema tentando um acordo entre o fornecedor e você. Os Procons atendem o consumidor com problemas nas áreas de: Alimentos, Assuntos Financeiros, Habitação, Educação, Produtos, Saúde e Serviços. 


\section{TAREFAS:}

\section{1) PRODUÇÃO ORAL}

Em duplas, simulem um diálogo com base na seguinte situação:

A: você comprou, em uma loja de eletrônicos, um novo celular, cuja bateria deveria durar 24 horas por recarga, conforme a propaganda do produto em um panfleto da própria loja. Logo na primeira semana de uso, você nota que a recarga da bateria dura apenas 4 horas. Você vai até a loja e procura o Serviço de Atendimento ao Consumidor (SAC). Explique o problema e sugira alguma providência para solucioná-lo, tendo por base as regras do Código do Consumidor.

B: você é atendente em um Serviço de Atendimento ao Cliente (SAC) de uma loja de eletrônicos. Um cliente dirige-se a você para reclamar sobre um celular, comprado na loja há duas semanas. Receba atentamente a reclamação e negocie a solução para o problema, de acordo com as regras do Código do Consumidor.

\section{2) PRODUÇÃO ESCRITA}

A conversa anterior com o atendente do SAC da loja de eletrônicos não solucionou o problema em relação ao seu celular. Escreva uma reclamação para enviar ao site do Procon. Explique novamente o ocorrido em detalhes (o problema inicial e a tentativa de solução). Peça auxílio ao órgão para sanar definitivamente a questão, de acordo com o Código do Consumidor. 